\title{
High Density Sludge process applied to metal-containing effluent
}

\author{
P. Suvio ${ }^{1}$, D. Sapsford ${ }^{1}$, A. J. Griffiths ${ }^{1}$, K. Williams ${ }^{1}$, J. D. Davies ${ }^{2}$ \\ \& S. Maynard ${ }^{2}$ \\ ${ }^{1}$ School of Engineering, Cardiff University, UK \\ ${ }^{2}$ Corus Strip Products, UK
}

\begin{abstract}
Large volumes of water are utilised during the operation of complex integrated steelworks. This usually results in the discharge of liquid effluents containing low concentrations of metals in solution and also the need to dispose of metal-rich sludges resulting from the treatment of these effluents. This paper presents the current performance of the final effluent plant at a large steelworks in South Wales, UK, focusing on the discharge effluent quality. In order to better understand the metal removal mechanisms a series of laboratory studies have addressed the precipitation of single metals and the co-precipitation of $\mathrm{Zn}$ with a range of other metals, including $\mathrm{Fe}$ and $\mathrm{Cu}$, using sodium hydroxide as the alkali. Experimental data is compared to the predicted values using the geochemical model, PHREEQCi 2. Large sludge volume reductions were found for effluent treatment using the so-called High Density Sludge (HDS) process, which was operated on a pilot scale. HDS was achieved by mixing recirculating sludge and the feed water prior to adding the alkali, creating a so-called two stage neutralisation process, where recirculated sludge acts as a seed for further metals precipitation. Careful performance monitoring of the HDS process pilot plant was carried out in order to ensure suitable conditions for the formation of HDS. By the end of the trial HDS with high initial settling characteristics was being formed.
\end{abstract}

Keywords: zinc, hydroxide precipitation, high $p H$ precipitation, steelworks, High Density Sludge, settling velocity. 


\section{Introduction}

The treatment of aqueous effluents to meet metal concentrations that are acceptable in final discharges to receiving waters is commonplace in a wide range of industrial applications, from mines to large chemical complexes. The current study was undertaken in conjunction with a large integrated steel manufacturing complex in South Wales, UK. Several effluent treatment systems are used at the site, handling flows from individual process facilities. As a means of capturing any residual metal species before final discharge, a conventional alkali precipitation and settlement system, using type II (flocculant) settling [1], has been in operation since 1999. This has been very successful in limiting concentrations of target metals in solution. However, in common with most plants of this type, especially when sodium hydroxide is the alkali of choice, the settled sludge concentrations are very low with maximum concentrations of 5\% solids (w/v) [2] in exceptional cases and further dewatering by filter press can be problematic. In many similar situations the so-called High Density Sludge (HDS) process, where precipitates are recycled to mix with the incoming feed, has been found to be highly effective at enhancing sludge dewatering behaviour [3]. This paper examines the existing plant performance and presents the results of a pilot-scale study of effluent treatment by the HDS II process [4], where the incoming effluent water is mixed with recirculated sludge, prior to adding the alkali reagent and air.

\section{Experimental}

\subsection{Full-scale plant performance studies}

In order to establish the current level of metal concentration in the final discharge entering and leaving the conventional alkali precipitation and settlement system in use at the steelworks, full-scale plant studies were carried out over a 7 month period, examining the levels of target metals in solution, including $\mathrm{Zn}, \mathrm{Fe}, \mathrm{Ni}, \mathrm{Cu}, \mathrm{Cr}, \mathrm{Pb}$ and $\mathrm{Cd}$. The system is using sodium hydroxide $(\mathrm{NaOH})$, which is mixed together with the incoming feed and Cationic Polyacrylamide by mixing motors in the first chamber of the system. The sample for the incoming water was taken from the mixing chamber, which has a $\mathrm{pH}$ controlling system in place, aiming to keep the $\mathrm{pH}$ as close as possible to, but above, 8.5. The sample for the outlet water was taken from the clean water weir at the end of the sedimentation system. Prior to testing the samples were filtered, followed by an analysis on a Perkin Elmer Optima DV5300 Inductively Couple Plasma (ICP) atomic emission spectrometer.

\subsection{Laboratory study of precipitation and co-precipitation}

Several studies have been carried out looking at the precipitation of metals out of solution. In order to determine how the target metals precipitate either on their own or together with other metals in solution, a co-precipitation study using base 
titration with sodium hydroxide $(\mathrm{NaOH})$ as an alkali was carried out. In this laboratory study $100 \mathrm{mg} / 1$ of metal concentration for each metal was added to a litre of tap water. The volume of sodium hydroxide $(\mathrm{NaOH})$ required to increase the $\mathrm{pH}$ to stable $7,8,9,10$ and 11 was measured. Furthermore, a sample was taken at each $\mathrm{pH}$ for analysis of the remaining soluble metal concentration on a Perkin Elmer Optima DV2100 Inductively Couple Plasma (ICP) atomic emission spectrometer. The $\mathrm{pH}$ meter used in the study was a Hanna HI208. Previous work on removing metal complexes from solution as metal hydroxides has showed that the actual solubility of metal ions and the minimum $\mathrm{pH}$ for maximum precipitation varies according to the mix of metal ions present in the solution [5].

\subsection{Modelling of expected solution properties}

PHREEQCi Version $2[6,7]$ is a free ware computer program written in the Cprogramming language that is designed to perform a wide variety of lowtemperature aqueous geochemical calculations, based on an ion-association aqueous model.

\subsection{Pilot-scale HDS plant}

A continuous trial with a HDS process pilot plant (Figure 1) was carried out during the two months leading up to 16.02.2010 in order to confirm that HDS could be produced using sodium hydroxide as the alkali reagent. $\mathrm{Zn}, \mathrm{Cu}, \mathrm{Fe}, \mathrm{Ni}$ and $\mathrm{Mn}$ were added to tap water to give the desired concentrations. The tap water was dosed with the appropriate amounts of $\mathrm{Mg}$ and $\mathrm{Ca}$ to mimic the background concentrations found at the steelworks (see Table 2).

\subsubsection{Plant description}

The plant consists of a $1 \mathrm{~m}^{3}$ Intermediate Bulk Container (IBC) feed water storage tank that was manually stirred daily to ensure the contents were fully mixed. A peristaltic feed pump (Watson Marlow SciQ 323) was used, aiming for a nominal incoming feed flow rate of 101/h (30 minute retention time in the first two reactors). The plant feed was mixed with the recycled sludge in the 51 Stage I reaction tank (cylindrical with a radius of $0.075 \mathrm{~m}$ and a height of $0.28 \mathrm{~m}$ ). A top mounted mixer (a Heidolph RZR 2041 operated at speed setting 1 at $302 \mathrm{rpm}$ ) was installed in the Stage I reactor to keep the solids in suspension.

The overflow from the Stage I reactor was fed into the similarly sized Stage II reactor, where the $\mathrm{pH}$ was raised by the addition $(\mathrm{NaOH})$. The alkali was supplied from a storage vessel and dosed to the Stage II reactor via an integral controller/metering pump (Hanna Instruments BL 7916). A pH controller was used to maintain the Stage II reactor $\mathrm{pH}$ appropriate for the metals in the feed water. The alkali dosing rate was controlled via a $\mathrm{pH}$ probe located at the outlet of the Stage II reactor. The $\mathrm{pH}$ controller was calibrated twice a week and the pH measurement was also checked using a Hanna Instruments HI208 portable $\mathrm{pH}$ meter. The alkali was stored in a 251 storage vessel and the stock solution was made up to a strength of $5 \%$ by dissolving $50 \mathrm{~g}$ of sodium hydroxide pellets 


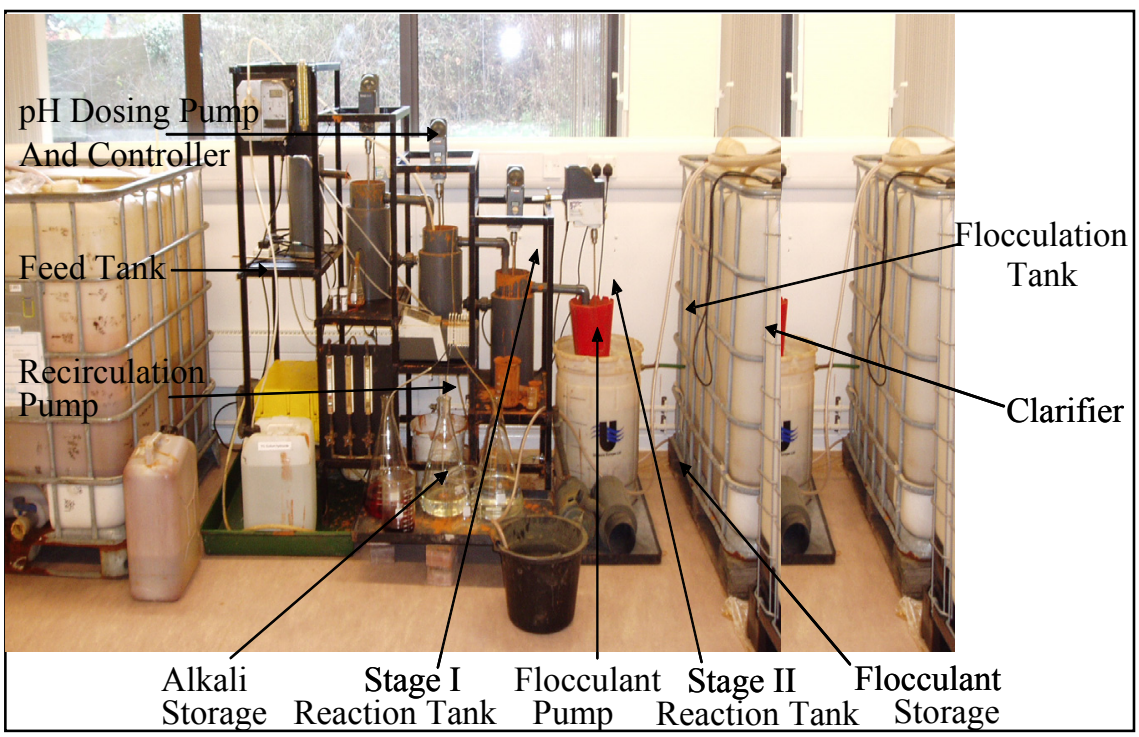

Figure 1: $\quad$ Photograph of the High Density Sludge pilot plant.

per 1 litre of hot tap water, which ensured that all the pellets dissolved. Air was introduced via a diffuser ring at a rate of $101 / \mathrm{h}$ to ensure the full oxidation of the metals. A top mounted mixer (a Heidolph RZR 2041 operated on speed setting 1 at 200rpm) was used to increase oxygen transfer rate and ensure adequate mixing.

The treated water from the Stage II reactor overflowed into the floc-mixing tank (volume 2.51, cylindrical with a radius of $0.075 \mathrm{~m}$ and a height of $0.14 \mathrm{~m}$ ). Flocculant was added to the feed line from the Stage II reactor. A slow-speed flocculation mixer (a Heidolph RZR 2041 operated on speed setting 1 at $141 \mathrm{rpm}$ ) was used for solids and flocculant mixing. The flocculated mixture then flowed via gravity into the clarifier. Anionic flocculant (Superfloc 110) was made up at a concentration of $0.05 \% \mathrm{w} / \mathrm{v}$ (i.e. $0.5 \mathrm{~g}$ of active flocculant $/ 1$ ). The dosing pump used was a FA Hughes (DCL) peristaltic pump. Solids/liquid separation was achieved in a clarifier/thickener cone, with a maximum surface area of approximately $0.0176 \mathrm{~m}^{2}$. Thickened solids from the clarifier were either recirculated to the Stage I reactor or removed from the system by peristaltic Watson Marlow 604U pump. A slow-speed mixer (a Heidolph RZR 2041 operated on speed setting 1 at $70 \mathrm{rpm}$ ) was used to assist solids/liquid separation. Treated water was discharged from the system by overflowing the clarifier unit.

\subsection{Pilot plant performance monitoring}

The performance of the pilot plant was assessed by monitoring several aspects, including the volume of feed water, flocculant and alkali added daily, as well as the pHs throughout the plant. The volume of sludge returned to the Stage I 
reactor was regularly monitored and the rate of removal of sludge was controlled. Further, regular samples were taken throughout the plant in order to carry out analysis for soluble metal concentration levels on Perkin Elmer Optima DV2100 Inductively Couple Plasma (ICP) optical emission spectrometer. Daily settling tests were carried out and solids concentration of the sludge was measured by filtering samples and measuring their weight against the sample volume $(\% \mathrm{w} / \mathrm{v})$ after drying in oven at $105^{\circ} \mathrm{C}$ for 2 hours. From the settling rate data collected the initial linear position of the curves were plotted against the respective solids concentrations to monitor how sedimentation changes with the age of the sludge.

\section{Results and discussion}

\subsection{Full-scale plant performance}

Results for soluble metal concentrations before (In) and after (Out) being treated by the steelwork's final discharge precipitation and settlement system can be seen in Table 1 below. The steelworks are working under consent limits for monthly average soluble metal concentrations in final discharge, including:

- Soluble Zn

$2.5 \mathrm{mg} / \mathrm{l}$ monthly average

- Soluble $\mathrm{Pb}$

$0.3 \mathrm{mg} / 1$ monthly average

- Soluble $\mathrm{Cr}$

$0.2 \mathrm{mg} / \mathrm{l}$ monthly average

As can be seen in Table 1, the steelworks final discharge precipitation and settlement system is working efficiently in removing soluble metals with near or over $90 \%$ removal performance for $\mathrm{Fe}, \mathrm{Zn}, \mathrm{Pb}$ and $\mathrm{Cr}$ and the average concentrations leaving the steelworks final discharge precipitation and settlement system are well under the consent limit.

\subsection{Laboratory-scale studies for precipitation and co-precipitation with expected solution properties}

Precipitation and co-precipitation experiments, especially looking for performance of zinc were carried out and compared against predicted

Table 1: Soluble metal removal performance of the steelworks final discharge precipitation and settlement system ${ }^{*}$.

\begin{tabular}{|c|c|c|c|c|c|c|}
\hline & \multicolumn{3}{|c|}{ In mg/l } & \multicolumn{2}{c|}{ Out mg/l } & Removal \\
\hline Metal & Max & Min & Ave & Max & Ave & \% \\
\hline $\mathrm{Fe}$ & 102.00 & 2.40 & 20.60 & 10.80 & 1.88 & 90.86 \\
\hline $\mathrm{Zn}$ & 29.00 & 0.30 & 6.11 & 2.90 & 0.74 & 87.87 \\
\hline $\mathrm{Pb}$ & 9.40 & 0.00 & 0.93 & 0.05 & 0.05 & 94.20 \\
\hline $\mathrm{Cr}$ & 0.10 & 0.00 & 0.03 & 0.00 & 0.00 & 87.50 \\
\hline $\mathrm{Ni}$ & 0.50 & 0.00 & 0.04 & 0.02 & 0.02 & 50.00 \\
\hline $\mathrm{Cu}$ & 0.90 & 0.00 & 0.07 & 0.05 & 0.05 & 23.53 \\
\hline
\end{tabular}

$* \mathrm{Cd}$ results and minimum soluble metal concentration levels are 0.00 for all sections. 
— Predicted PHREEQC

- Co-precipitation Zn with Fe
$\Delta$ Precipitation of $\mathrm{Zn}$ only Co-precipitation $\mathrm{Zn}$ with $\mathrm{Cu}$

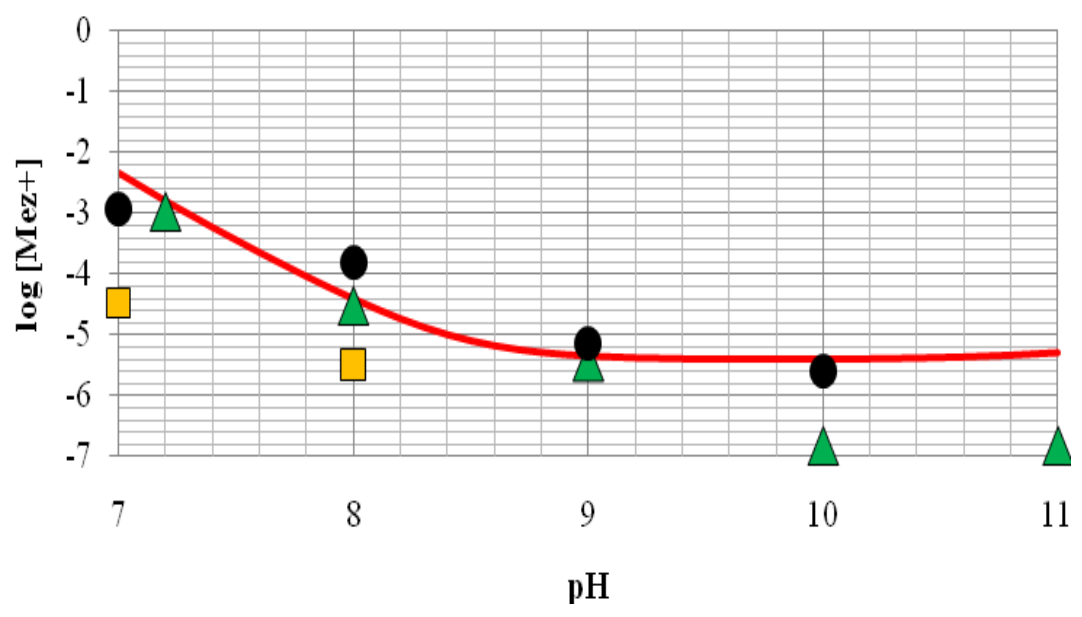

Figure 2: Comparison between predicted (PHREEQC) and experimental soluble metal concentrations at various $\mathrm{pHs}$.

PHREEQCi 2 values (Figure 2). As a simple element, the zinc precipitation results follow predicted PHREEQC values very closely at pH's 7 to 9 and give ever lower concentration values at $\mathrm{pH}$ 's 10 and 11 . When co-precipitating with copper, zinc precipitation results were close to the theoretical, but were found to be higher than the predicted values at $\mathrm{pH}$ 's 8 and 9. At $\mathrm{pH} 11$, there was no zinc left in the solution. When co-precipitating with $\mathrm{Fe}^{2+}$, zinc precipitation values were well under the predicted values at $\mathrm{pH}$ 's 7 and 8 . At $\mathrm{pH}$ 's 9 to 11, there was no $\mathrm{Zn}$ left in the solution when co-precipitating with soluble $\mathrm{Fe}^{2+}$.

Around $\mathrm{pH}$ 8.5, these results resemble closely the performance of the steelworks final discharge precipitation and settlement system for zinc left in solution.

\subsection{Pilot plant data}

Plant performance analysis can be carried out looking at several aspects of the performance during the trial. The results for soluble concentrations before (In) and after (Out) being treated by the HDS pilot plant can be seen in Table 2. The results show that the HDS pilot plant was able to not only create sludge with good settling qualities (See Figure 8), but also discharge water with very low concentrations of soluble metal.

The variation of $\mathrm{pH}$ with time in the feed and throughout the HDS pilot plant streams can be seen in Figure 3. Throughout the trial, the feed $\mathrm{pH}$ is hovering around 7 , with the Stage I Reactor and discharge $\mathrm{pH}$ being around $\mathrm{pH} 8$. 
Table 2: $\quad$ Soluble concentrations in the HDS pilot plant feed and discharge water.

\begin{tabular}{|l|r|r|r|r|r|r|}
\hline \multirow{2}{*}{$\begin{array}{l}\text { Consti- } \\
\text { tuent }\end{array}$} & \multicolumn{3}{|c|}{ In mg/l } & \multicolumn{3}{c|}{ Out mg/l } \\
\cline { 2 - 7 } Zn & \multicolumn{1}{|c|}{ Min } & \multicolumn{1}{c|}{ Max } & \multicolumn{1}{c|}{ Ave } & \multicolumn{1}{c|}{ Min } & \multicolumn{1}{c|}{ Max } & \multicolumn{1}{c|}{ Ave } \\
\hline Cu & 24.5 & 76.8 & 42.7 & 0.0 & 5.2 & 1.4 \\
\hline $\mathbf{N i}$ & 4.5 & 3.4 & 1.3 & 0.0 & 0.4 & 0.0 \\
\hline Fe & 0.0 & 0.0 & 6.0 & 0.0 & 3.4 & 1.0 \\
\hline Mn & 12.8 & 26.2 & 16.1 & 0.0 & 11.3 & 6.1 \\
\hline Mg & 17.5 & 36.8 & 22.3 & 5.2 & 27.9 & 20.3 \\
\hline Ca & 200.7 & 470.9 & 339.2 & 87.4 & 391.7 & 290.6 \\
\hline
\end{tabular}

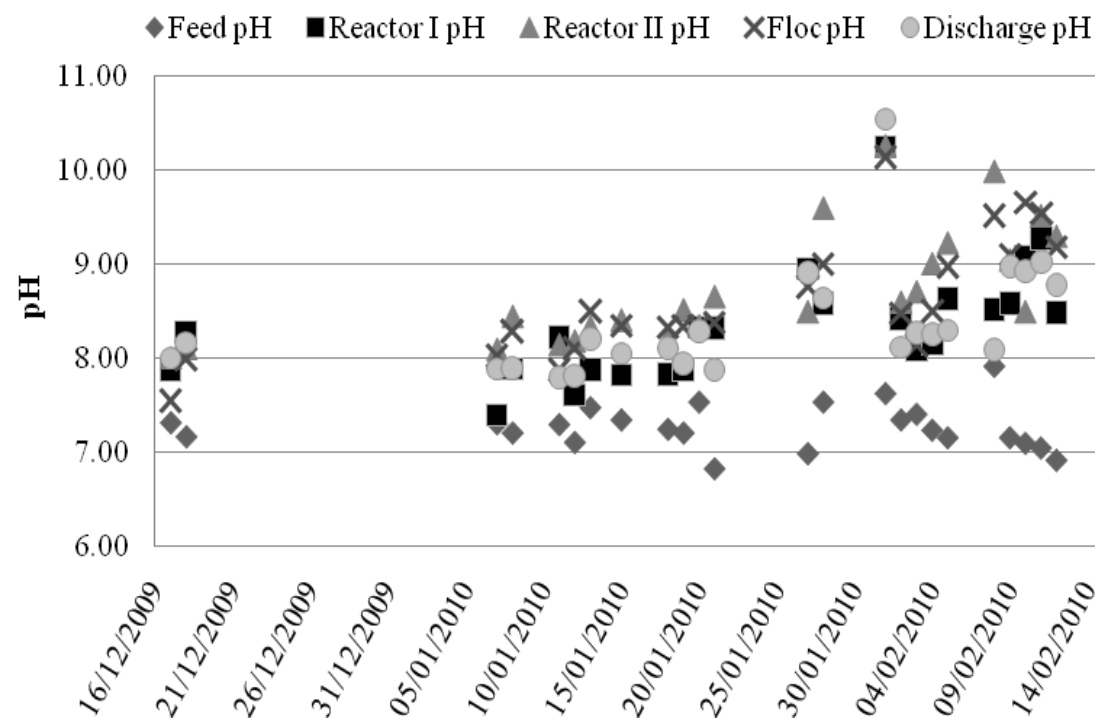

Figure 3: $\mathrm{pH}$ variation with time in feed and throughout the HDS pilot plant streams.

Towards the end of the trial, the operating $\mathrm{pH}$ was raised slightly to ensure all the metals were being removed from solution. This, together with the higher amount of sludge return at the end of the trial, also affected the amount of soluble manganese left in the solution as can be seen in Figure 4.

The performance of removing soluble $\mathrm{Zn}$ (Figure 5) during the trial was also getting better towards the end and lower discharge concentrations of soluble $\mathrm{Zn}$ were found at the end of the trial, even though the concentration of the $\mathrm{Zn}$ on the feed water was raised from $50 \mathrm{mg} / 1$ to $100 \mathrm{mg} / 1$. 


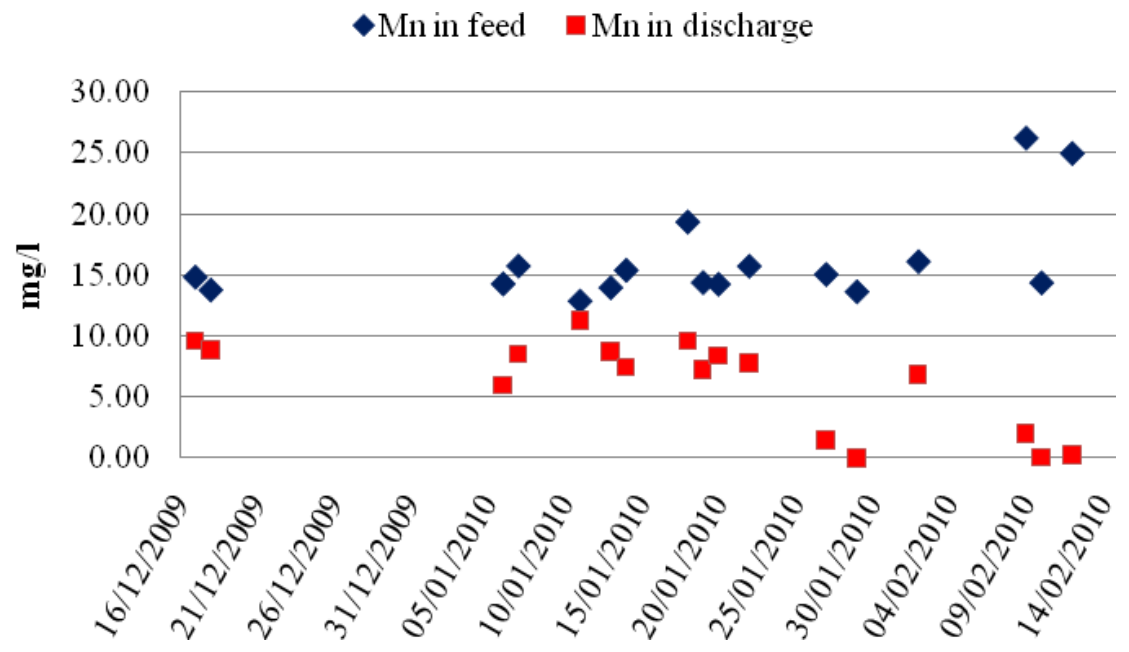

Figure 4: Soluble Mn concentrations with time in the HDS pilot plant feed and discharge water.

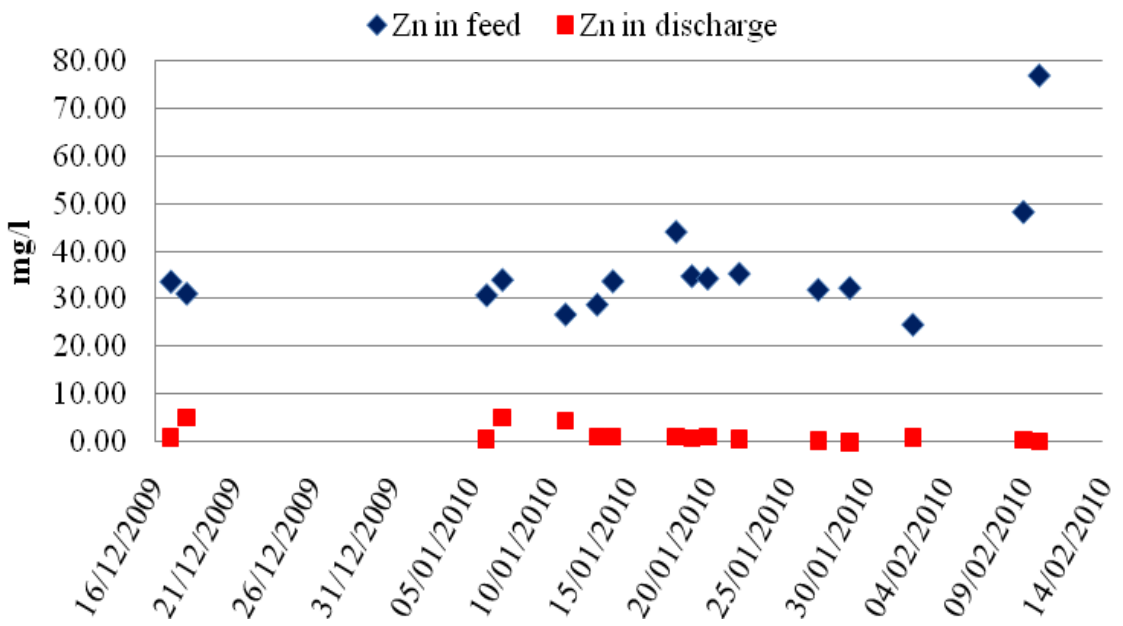

Figure 5: Soluble $\mathrm{Zn}$ concentrations with time in the HDS pilot plant feed and discharge water.

Looking at the Mn and $\mathrm{Zn}$ removals in more detail it is interesting to note that the soluble Mn levels in the discharge remained close to about $8 \mathrm{mg} / \mathrm{l}$ up to around 20/01/2010 when the operating $\mathrm{pH}$ of the Stage II Reactor was raised close to 9 . The effect of increasing amounts of recirculating sludge seemed to be minimal. Once the $\mathrm{pH}$ was raised the $\mathrm{Mn}$ concentration in the discharge decreased accordingly. For $\mathrm{Zn}$, however, there appears to be a stabilisation of 
- Recirculating solids versus incoming metal hydroxideratio

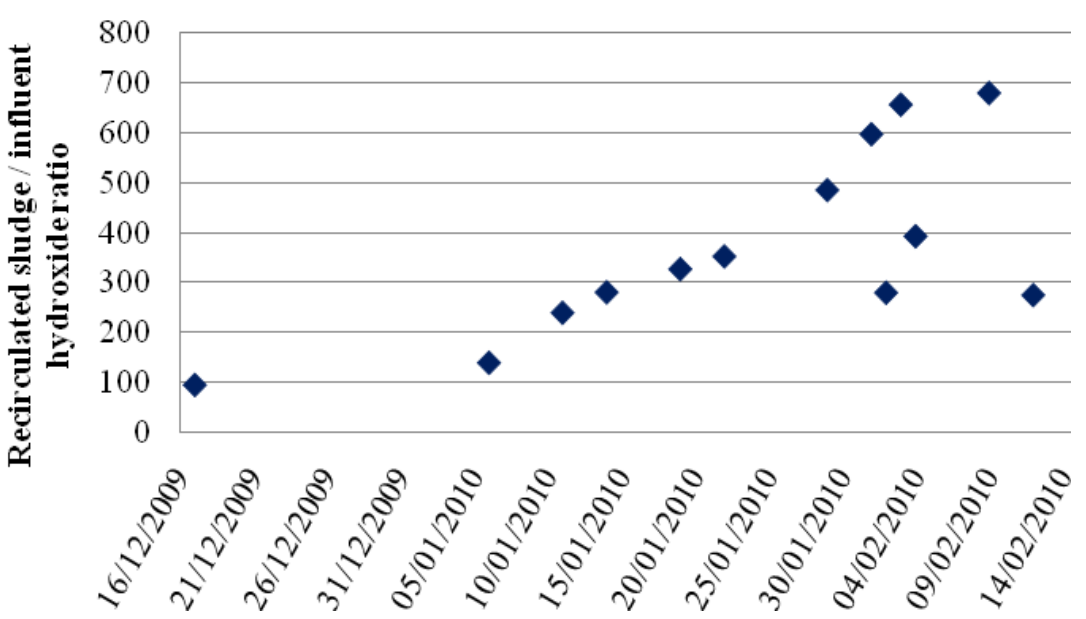

Figure 6: Recirculating solids to incoming metal hydroxide ratio during the HDS pilot plant trial.

the soluble concentration in the pilot plant effluent well before the $\mathrm{pH}$ was increased.

Figure 6 shows the metal hydroxide mass recirculation ratio during the trial. The ratio varied between 95.1:1 and 680.4:1 during the whole trial. The largest ratios occurred at the later stages of the trial when the returning sludge concentrations were higher.

As can be seen in Figure 7, the flocculant dosage rate during the trial was between 2 and just under $6 \mathrm{mg}$ of flocculant per litre of feed water treated. The best settling characteristics were found with a flocculant rate of around $2.5-3 \mathrm{mg}$ of flocculant per litre of feed water treated.

There was a very dramatic improvement in the settling rates as the trial progressed as can be seen in Figure 8, which displays the settling rates as a function of the corresponding solid concentrations for discrete ages of the sludges as reflected by the volumes treated. The ability of a floc to settle depends on its size and density. As the HDS process develops the floc density increased and an enhanced settling characteristic is obtained. The data clearly shows the development of floc density (HDS formation) as more and more precipitation occurs. In total, a volume of about 6000 litres was treated over two months of the trial, culminating in exceptionally high settling rates in excess of $22 \mathrm{~m} / \mathrm{h}$ at a relatively high solids concentration of $5 \%(\mathrm{w} / \mathrm{v})$. For very young sludges it was not possible to achieve high settling velocities even at solids concentrations as low as $0.1 \%(\mathrm{w} / \mathrm{v})$. Towards the end of the trial it was demonstrated by following the whole settling curve for 24 hours that settled solids concentration in excess of $70 \%(\mathrm{w} / \mathrm{v})$ were achieved compared to the literature values of less than $5 \%(\mathrm{w} / \mathrm{v})$ for conventional sludge on the large. 


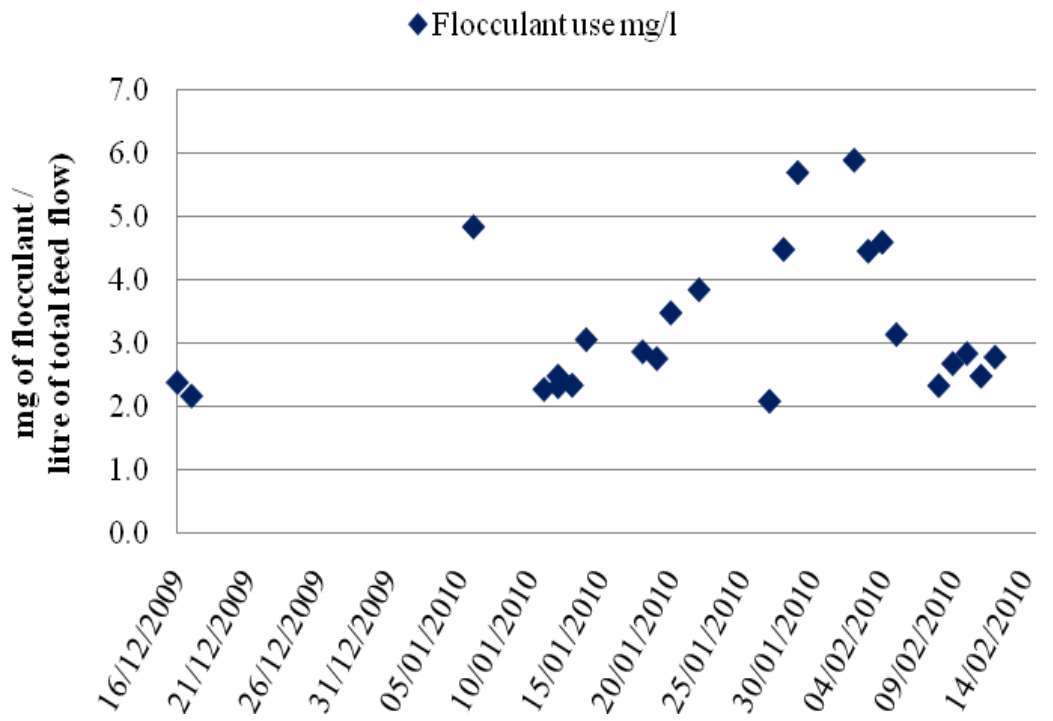

Figure 7: Flocculant dosage rate during the HDS pilot plant trial.

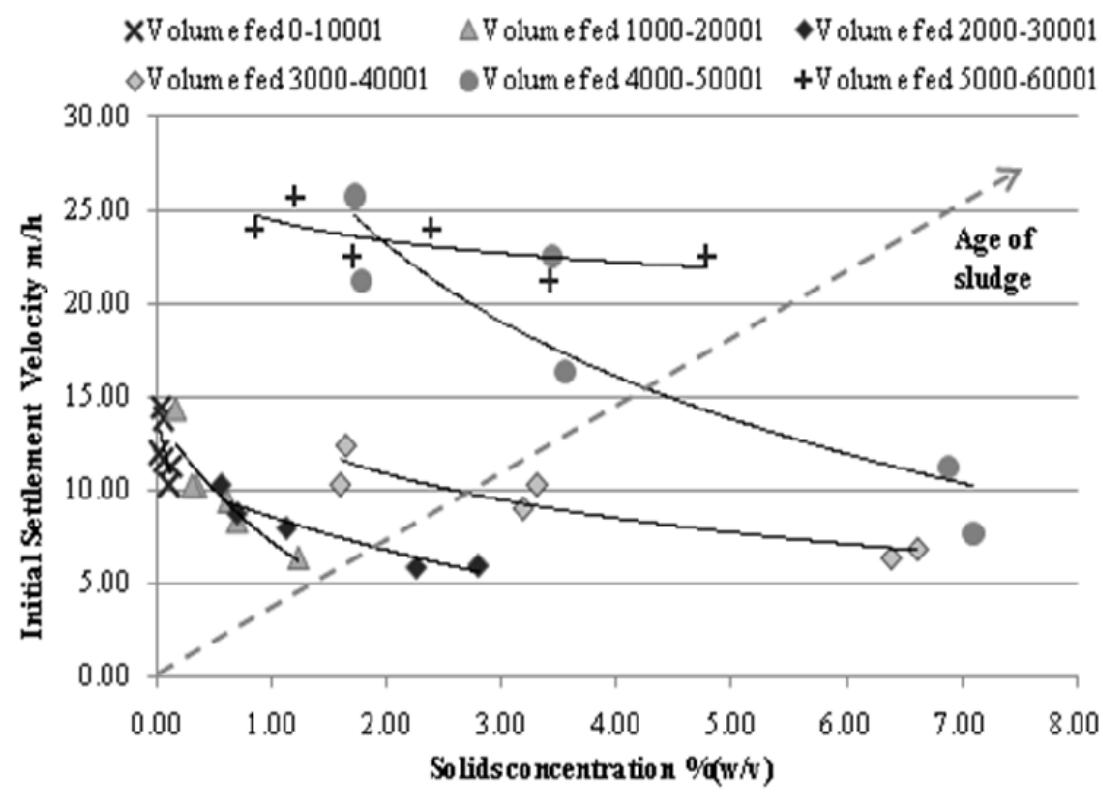

Figure 8: Initial settling rates as functions of volume fed to the HDS pilot plant (data represents approximately two months of operation). 


\section{Conclusions}

The steelworks current final discharge precipitation and settlement system is performing well, but the voluminous sludge produced is problematic to deal with.

PHREEQCi 2 theoretical and the experimental soluble metal concentrations match quite well through the various $\mathrm{pHs}$.

Co-precipitation of $\mathrm{Zn}$ with $\mathrm{Fe}$ is shown to produce residual soluble metal concentrations much lower than expected as a single species.

HDS forms very readily with this particular steelworks feed, giving precipitates with excellent settling characteristics.

\section{References}

[1] Gray N. F., Water Technology: An Introduction for Environmental Scientists and Engineers, $2^{\text {nd }}$ Edition, Elsevier Butterworth Heinemann: Oxford, pp. 535-571, 2005.

[2] Dempsey, B.A. and Jeon, B-H., Characteristic of sludge produced from passive treatment of mine drainage, Geochemistry: Exploration, Environment, Analysis, Vol. 1, pp. 89-94, 2001.

[3] Bullen C. J., An Investigation into the Mechanisms Controlling the Formation of High Density Sludge, PhD. Thesis, University of Wales, Cardiff, 2006.

[4] Coulton, R. H., Bullen, C. J. and Hallet, C., The Design and Optimisation of Active Minewater Treatment Plants', Land Contamination and Reclamation, Vol 11, No 2, pp 273-279, 2003.

[5] Swindley, S.P., Control of effluent in steel production, Engineering Doctorate (EngD) Dissertation, University of Wales, Cardiff, 1999.

[6] Parkhurst, D.L., PHREEQC - a computer program speciation, batchreactions, one-dimensional transport, and inverse geochemical calculations, US Geological Survey Water resources Investigations, Report 95-4227, 1995.

[7] Parkhurst, D.L., Appelo, C.A.J., User's guide to PHREEQC (version 2) - a computer program for speciation, batch-reactions, one-dimensional transport, and inverse geochemical calculation, US Geological Survey Water resources Investigations, Report 99-4259, 1999. 